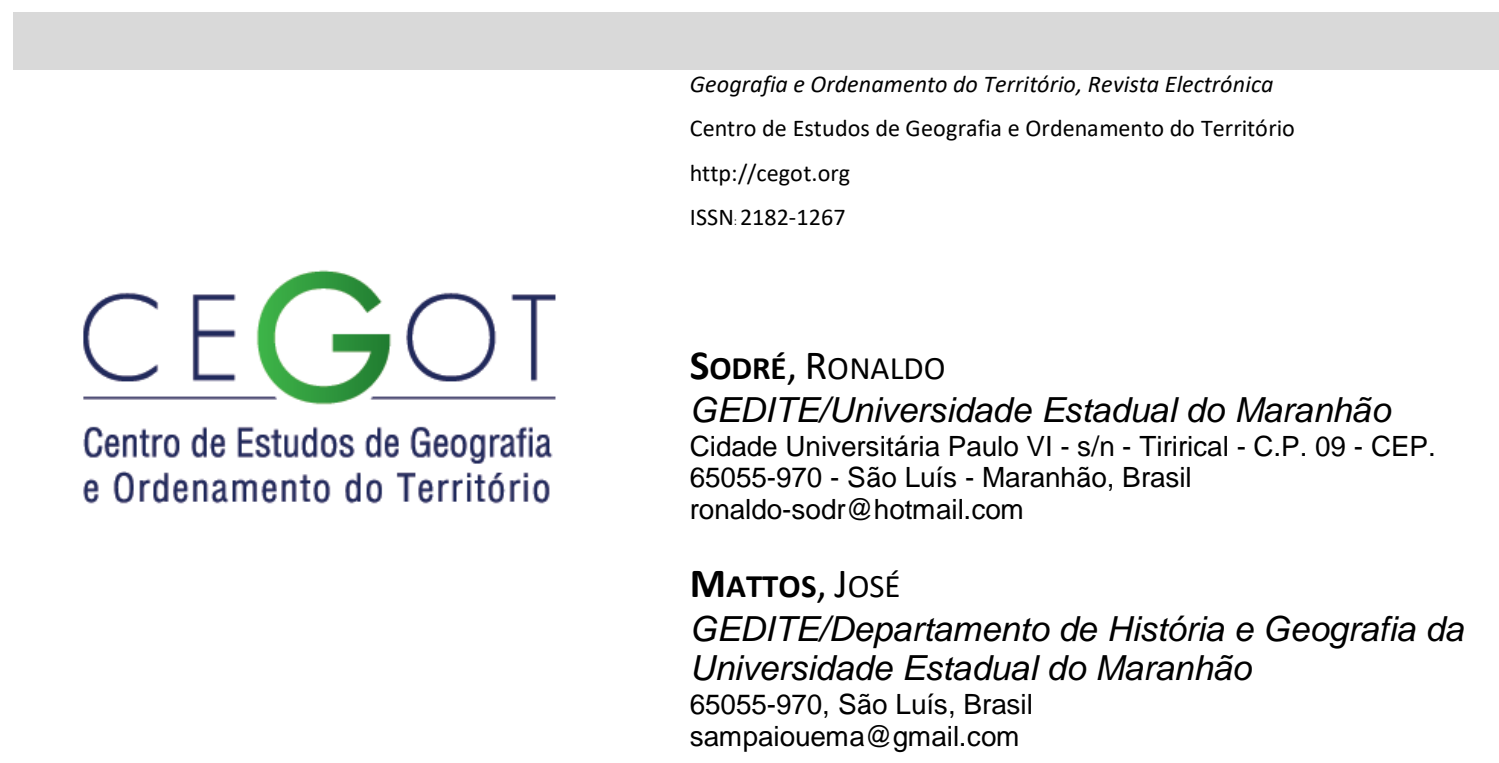

\title{
O emaranhado dos conflitos de terra no campo maranhense
}

\author{
Land conflicts in the fields of Maranhão
}

Referência: Sodré, Ronaldo; Mattos, José (2016). O emaranhado dos conflitos de terra no campo maranhense. Revista de Geografia e Ordenamento do Território (GOT), n. 10 (dezembro). Centro de Estudos de Geografia e Ordenamento do Território, p. 345-354, dx.doi.org/10.17127/got/2016.10.016

\section{RESUMO}

No Maranhão, estado brasileiro com o maior número de conflitos por terra do Brasil, um conjunto de enredados intensifica e avoluma a questão agrária, que nesse Estado adquire alguns contornos particulares, dada a heterogeneidade do campesinato maranhense, a concentração de capital, as desiguldades sociais, a expansão da fronteira agrícola etc. Neste trabalho apontamos alguns elementos que contribuem para os altos número de conflitos por terra, onde eles estão espacializados, bem como apontamos algumas soluções para mediação dessas relações conflituosas.

Palavras-chave: Conflitos. Terra. Rural. Questão Agrária. Maranhão. Brasil.

\section{ABSTRACT}

In Maranhão, Brazilian state with the largest number of land conflicts in Brazil, a set of entangled intensifies and enlarges the agrarian issue, where the state acquires some particular contours, given the heterogeneity of Maranhão peasantry, the concentration of capital, social inequalities, the expansion of the agricultural border etc. In this paper we point out some elements that contribute to the high numbers of land conflicts, where they are spatially as well as we pointed out some solutions to the mediation of these conflictive relationships. 
Keywords: Conflicts. Land. Rural. Agrarian Issue. Maranhão. Brasil.

\section{Introdução}

A terra enquanto fator de produção é um recurso utilizado nas relações sociais entre campos opostos, que se configura materialmente como sendo o poder. A questão agrária brasileira concede a essas relações um caráter primazmente conflituoso na disputa pelo território, que motiva e nutre a conflitualidade.

O objetivo inicial deste trabalho é identificar alguns elementos que deram forma ao emaranhado de conflitos de terra formado no Maranhão; o que vem provocando os conflitos registrados na história recente do estado? Como os conflitos estão distribuídos no espaço agrário maranhense? Para alcançar os objetivos propostos, preliminarmente realizamos levantamentos, análises e discussão de referenciais que abordam relações de poder, conflitos sociais, questão agrária e conflitos de terra no Maranhão. Concomitante a essa etapa da pesquisa, recorremos aos Cadernos de Conflitos da Comissão Pastoral da Terra (CPT), onde quantificamos os conflitos de terra no Brasil e no Maranhão no período que compreende nossa temporalidade de análise, 2001 a 2015.

\section{Do poder ao conflito}

Para Michel Foucault (1998) o poder deve ser compreendido como um suporte móvel da diversidade de correlações de forças imanentes ao domínio onde se exercem sua organização. O poder possui uma onipresença e se produz constantemente, em toda relação entre um ponto e outro, de forma que não se pode reduzi-lo a uma instituição ou a uma estrutura, tampouco, como uma forma de regra ou um modo de sujeição por oposição a violência.

Para Norberto Bobbio (1998) o poder não deriva simplesmente da posse ou do uso de certos recursos, mas também da existência de determinadas atitudes dos sujeitos em suas 
relações. Essas atitudes dizem respeito aos recursos e ao seu emprego, e de maneira geral, ao poder.

Dessa forma, as relações de poder não se processam unicamente através das relações dos sujeitos hegemônicos sobre os hegemonizados. Ainda que a divisão de classes deixe mais visíveis essas correlações, que Foucault (2005: 141) considera como piramidalizadas, mais ou menos ordenadas e mal coordenadas. As relações de poder são assim, desiguais e relativamente estabilizadas. Hora podendo vir de cima para baixo, hora de baixo para cima como no caso dos micro-poderes.

Existem diferentes modos pelos quais o poder pode ser exercido na sociedade, de acordo com Bobbio (1998) eles variam da persuasão à manipulação, ameaça de uma punição ou mesmo, uma promessa de recompensa.

Uma situação de conflito social é resultado de um exercício de poder, embora nem toda relação de poder tenha como efeito o conflito. O conflito é produto de toda estrutura social e está envolvido em um processo dialético, em que sendo solucionado ocasionará mudanças. Para Pasquino (1998: 225) o "conflito é uma forma de interação entre indivíduos, grupos, organizações e coletividades que implica choques para o acesso e a distribuição de recursos escassos".

Cada situação de conflito terá seus recursos particulares, podendo eles assumirem uma ou mais causas, o território por exemplo, - instituído a partir da afirmação de um indivíduo ou grupo de indivíduos em um espaço apropriado - pode ser um recurso de conflitos sociais, políticos, econômicos etc.

A terra como elemento analítico do território, por excelência é um recurso em disputa. Diversos instrumentos são utilizados nas situações conflituosas que a envolvem. As sociedades que não conseguem diluir ou diminuir essas disputas, tendem a criar um campo de barbárie, que não necessariamente ocorre segundo a contraposição de classes ou grupos opostos.

A partir dessas reflexões, entendemos que as relações sociais desempenham o papel de inserção e de orientação do homem em um contexto próprio dentro de uma divisão social. Essas relações, em seus vários aspectos, são condicionadas ao poder, que subsistem e agem 
conforme essa correlação. O poder é um tipo de relação social, mais também uma prática, que pode ser exercida por meio de instrumentos ou de coisas.

\subsection{Questão agrária e conflitualidade no campo maranhense}

A incapacidade estrutural do Estado brasileiro em lidar com o uso e controle da terra, - de forma particular, com a propriedade privada da terra - criou ao longo dos anos uma estrutura agrária desigual, responsável por grande parte dos problemas sociais do país, levando a uma questão agrária.

A questão agrária, outrora compreendida como sinônimo de "problemas agrários", tomou dimensões que a tornaram superior no espaço e no tempo e que não se restringe ao campo, podemos dizer que "[...] é uma coisa do passado, mas é do presente, está ali, aqui e naquilo, em todo o lugar, ação e objeto" (FERNANDES, 2005: 4).

A dinamicidade da questão agrária torna menos incompreensíveis a definição e a compreensão, tão quanto a sua materialidade. Stedile (2012: 641) descreve a questão agrária como uma área do conhecimento que estuda a natureza dos problemas das sociedades relacionados ao uso, posse e propriedade da terra, ou seja, respectivamente a forma como o homem se apropria da natureza para organizar a produção agrícola, quem são os sujeitos que moram e vivem em um determinado território e a condição jurídica - a partir do capitalismo - da terra, bem como os meios que levaram a sua propriedade. Essa tríade formada com a penetração de estruturas primitivas de capital ainda no sistema feudal, relaciona-se também com a questão agrícola, o que faz da questão agrária também uma questão rural.

Fernandes (2005) considera a questão agrária fruto da contradição estrutural do capitalismo, que simultaneamente produz a concentração da pobreza e da miséria, impossibilitando a superação da questão agrária, pelo contrário, a sua perpetuação ocorre por meio de seu paradoxo (o movimento da questão agrária). Nessa perspectiva, o pesquisador analisa a questão como inerente a outra dimensão, a da conflitualidade, ou seja, a partir do enfrentamento dessas contradições. 
A conflitualidade é uma propriedade continua dos conflitos e está relacionada, essencialmente, à propriedade da terra, à renda da terra, da estrutura fundiária e aos processos de expropriação dos camponeses e assalariados por diversos meios e escalas e bases sociais, técnica econômica e política. A resposta é a luta pela terra, reforma agrária, resistência na terra e a perspectiva de superação da questão agrária (FERNANDES, 2005: 27).

Transcendente a um conflito, a conflitualidade não pode ser resolvida, pois está em constante reprodução pelas relações sociais dentro do território. Ainda segundo Fernandes (2005: 26) o conflito é o estado de confronto entre forças opostas a partir de suas relações sociais, em condições políticas adversas, que buscam por meio da negociação, da manifestação, da luta popular, do diálogo, a real possibilidade de superação do litigio.

A conflitualidade (re)produz os conflitos por terra, que retroalimentam a questão agrária. Esse tipo de conflito, que é pelo território e seus recursos, ocorre no âmbito da luta de classes opostas, onde sai vencedora a classe que melhor utilizar seus mecanismos no exercício do poder.

Cabe ainda diferenciar os conflitos por terra e os conflitos na terra, esses últimos não se limitam a uma luta antagônica, podendo ser uma relação divergente intraclasse no território conquistado. Temos como exemplo um assentamento rural composto por famílias de diferentes regiões geográficas, a diversidade de famílias pode motivar desencontros pessoais e culturais e ocasionar conflitos que vão além do conflito de opiniões.

\subsection{Um emaranhado de conflitos}

A conflitualidade é um processo contínuo alimentado por contradições que se manifestam nos múltiplos territórios com formas singulares. O Maranhão, estado com a população mais rural do país ${ }^{1}$, além da diversidade de elementos comuns à questão agrária encontrada em outros estados brasileiros, exibe um conjunto de particularidades.

As desigualdades sociais são extremas, a pobreza e a miséria assolam grande parte da população, com frequência o Maranhão encabeça a lista dos Estados com os piores indicadores sociais do país como demonstra o Índice de Desenvolvimento Humano (IDH), por outro lado uma minoria da população vive quase de forma antagônica.

\footnotetext{
${ }^{1}$ Segundo dados do Instituto Brasileiro de Geografia e Estatítica (IBGE),(2010) dos 6.569 .683 habitantes do Estado, 2.425.955 vivem na zona rural.
} 
Historicamente a concentração de capital no campo maranhense pode ser percebida pelos ciclos econômicos que legaram períodos de riqueza ao estado. Atualmente verificamos que o agronegócio corresponde a faceta mais moderna de acumulação de capital no campo, observamos um processo constante que envolve novas territorialidades, novas formas de expropriação o que, consequentemente, levará a novos conflitos e tensões sociais no campo.

Em qualquer período da história, recente, do Maranhão é possível se deparar com conflitos no campo e a intensificação desses a partir da entrada de capital, foi assim na fase áurea dos ciclos econômicos ligados aos monocultivos (algodão e cana-de-açúcar); da mesma forma com a Lei Sarney de Terras ${ }^{2}$ e também com os vários projetos desenvolvimentistas implantados no estado a partir da década de 1980, em nome do capital ${ }^{3}$.

Segundo Almeida (1983 apud CARNEIRO, 2013), com base nos dados da CPT, entre os anos de 1979 e 1981 o Maranhão respondeu por 22,5\% dos casos de conflitos de terra registrados em todo o país. Os números são reflexos da conjuntura agrária formada ao longo dos séculos e que ganhou novos elementos a partir dos empreendimentos já citados.

Continuamente novas relações do capital no campo são criadas, o agronegócio e o seu conjunto de novas relações sociais, industriais, comerciais que envolve a cadeia produtiva. Esses processos não se restringem a questão agrícola, para sua instalação é preciso preparar terrenos numa escala macro para que o agronegócio crie sua territorialidade no micro - ou seria o inverso? - Os desdobramentos da questão agrária no Maranhão durante o século XX nos leva a crer que a terra foi semeada para que o agronegócio fosse plantado no estado.

\footnotetext{
${ }^{2}$ A Lei Sarney de Terras assinada nos 1960 foi um dos elementos que mais intensificou a questão agrária maranhense ao propiciar conflitos entre camponeses e grandes grupos empresariais. Segundo Gistelinck, 1998 (apud AZAR, 2009: 32) mais de 90\% das terras disponíveis no Estado foram apropriadas por grupos empresarias. Intensificaram-se os conflitos fundiários, o desmatamento irracional, a pecuária extensiva e a especulação fundiária.

${ }^{3}$ É nessa década que iniciam as operações da Estrada de Ferro Carajás (EFC), do Terminal da Ponta da Madeira (porto da Vale) e da ALUMAR, todos os produtos logísticos do antigo Projeto Grande Carajás (PGC). Para garantir a atividade de mineração foram implantadas desde 1988 diversas siderúrgicas para a produção de ferro gusa, concentradas principalmente no município de Açailândia. No segundo lustro da década de 1980, foi instalado no município de Alcântara o Centro de Lançamento de Alcântara (CLA).

Entre os anos de 1986 e 1987, mais de 300 famílias quilombolas de mais de 20 povoados do município do município de Alcântara foram compulsoriamente remanejadas para sete agrovilas no interior do mesmo município. Na área que viviam as famílias - considerada geograficamente bem localizada para lançamentos espaciais - foi instalado o Centro de Lançamento de Alcântara (CLA), uma organização de comando da Aeronáutica. Aos quilombolas restou se adaptar as novas terras, menores em extensão territorial, com solos ruins para a agricultura e distantes do mar, de onde tiravam quase toda a alimentação (MORIM: 2014).
} 
A territorialização do agronegócio quase sempre está relacionada a desterritorialização camponesa, que resulta no aumento do número de conflitos. No final dos anos 1980 a principal cultura do agronegócio maranhense adentra em grandes áreas de cerrado. $\mathrm{A}$ produção da soja se concentra na região Sul e a partir da década de 2000 se expande para municípios da região Leste como Anapurus e Brejo. O que explica o Leste ser a região do Maranhão com os maiores números de conflitos por terra nos últimos anos (ver Mapa 1).

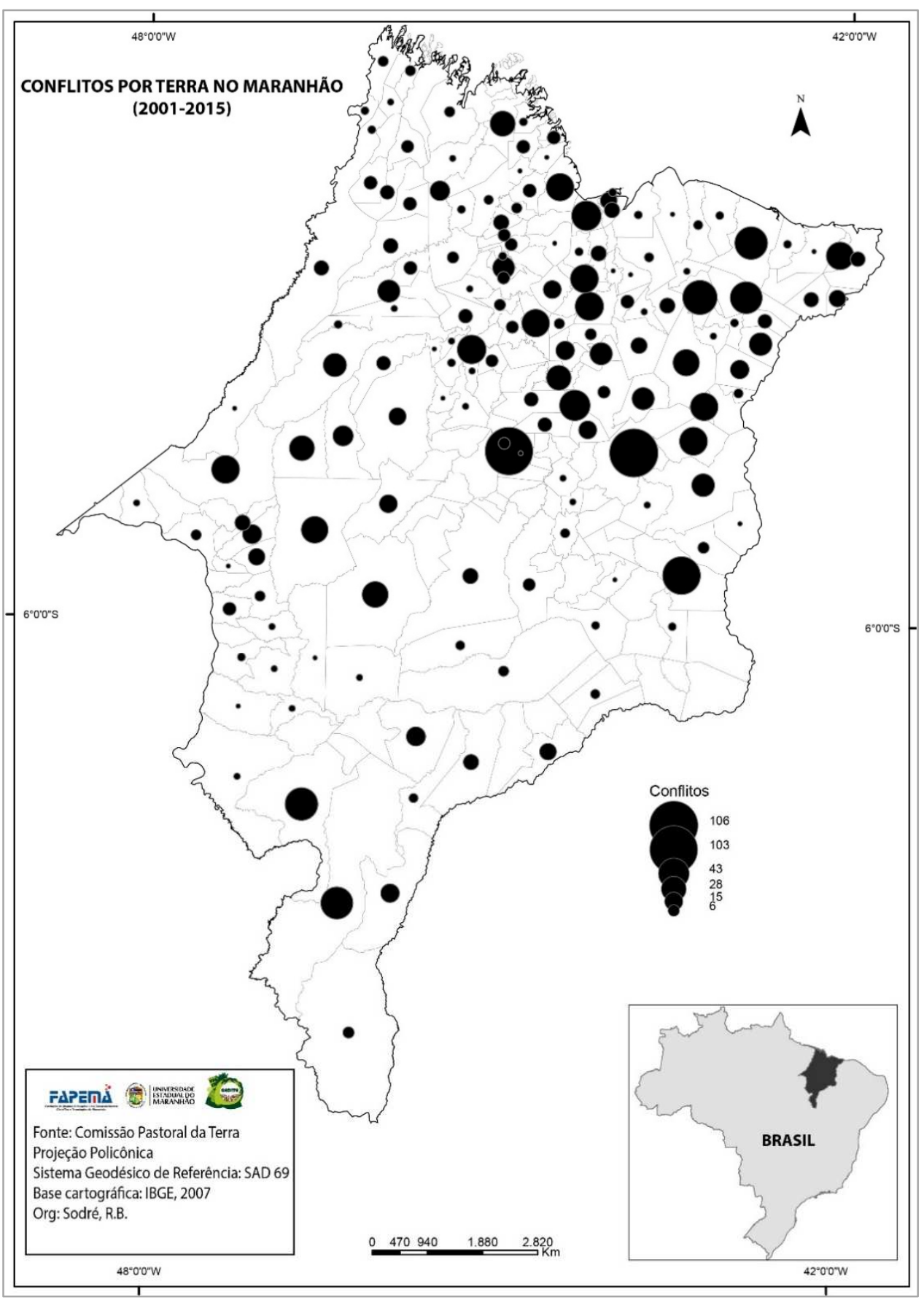

Mapa 1 - Conflitos por terra no Maranhão (2001 - 2015) 
Embora os conflitos por terra ocorram de acordo com a seletividade do capital sobre determinado espaço, no Maranhão eles não se restringem a uma única região. Conflitos de diversas ordens de grandeza são registrados em todo o território, colocando o Maranhão como o estado com os maiores números de conflitos por terra do Brasil (Ver Gráfico 1).

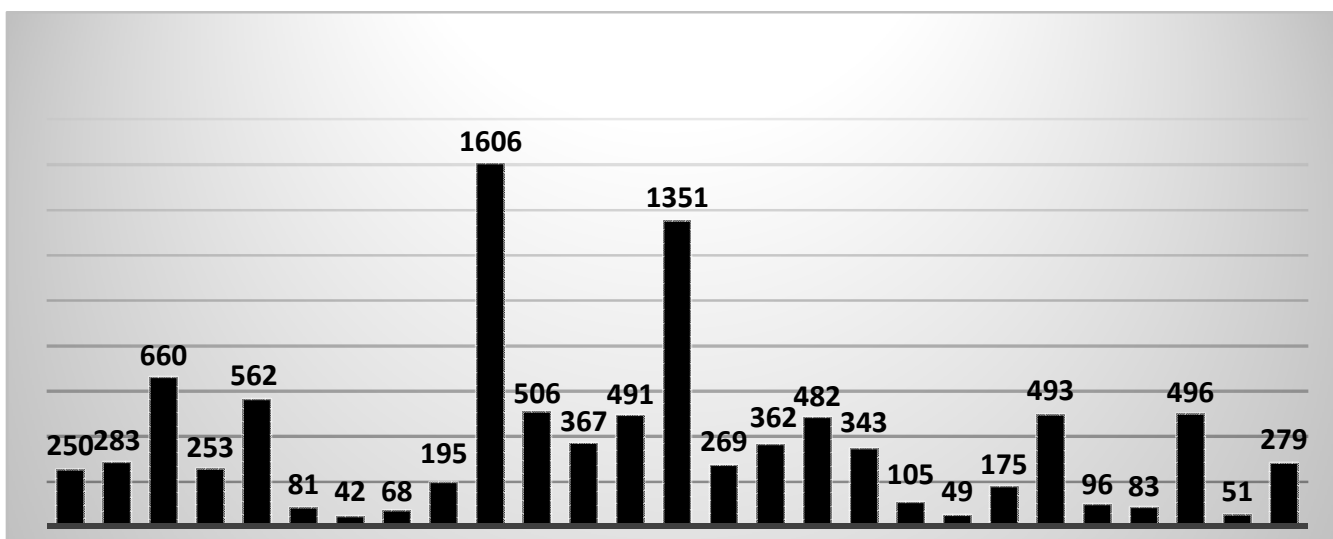

AC AL AP AM BA CE DF ES GOMAMT MSMG PA PB PR PE PI RJ RN RS RO RR SC SP SE TO

Gráfico 01 - Conflitos por terra por estado brasileiro (2001-2015)

Fonte: CPT, 2001 - 2015

Ainda de acordo com a CPT os conflitos por terra no Maranhão seguem aumentando (Ver Gráfico 2).

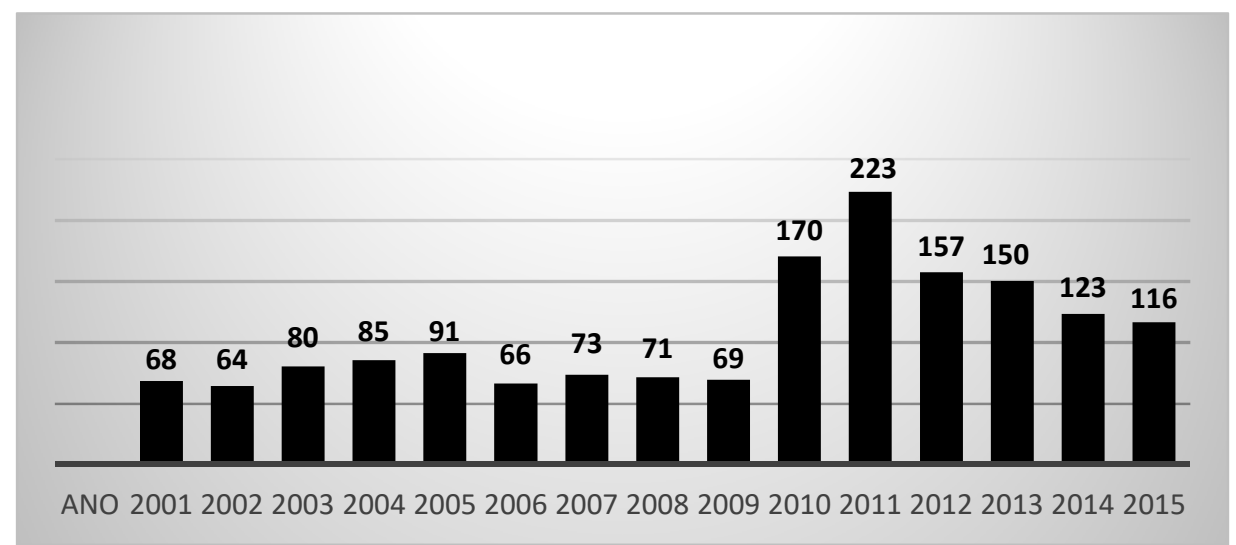

Gráfico 02 - Conflitos por terra no Maranhão (2001-2015)

Fonte: CPT, 2001 - 2015

Os números registrados à polícia e à CPT, mostram apenas uma quantidade de ocorrências, que podem alcançar números ainda mais expressivos. Em todo o Maranhão há uma porção incalculável de conflitos velados, o que dificulta o seu conhecimento e solução. 
A raiz de tantos conflitos está no processo contraditoriamente conservador de modernização da agricultura, que trouxe consigo a apropriação fraudulenta de terras, concentração fundiária, trabalho escravo, desemprego, diferentes formas de violência no campo e um dos mais elevados índices de desigualdades sociais do país.

\section{Considerações finais}

A questão agrária brasileira criou complexas curvas e em alguns estados grandes emaranhados. A opção do Estado por um modelo de desenvolvimento rural em detrimento de outro, resulta em situações conflituosas. A realização de uma classe é consequência de uma relação de poder vitoriosa de uma classe sobre outra.

O Maranhão, estado com a população mais rural do país é também o que registra os maiores números de conflitos por terra no Brasil. As áreas de expansão do agronegócio no estado são as que possuem os maiores focos de conflitos por terra, o que relaciona os conflitos ao capital.

O Estado como instituição maior, deve mediar essas situações, mas acaba alimentando-as por meio de um modelo de desenvolvimento de reprimarização econômica, que não prioriza a função social da terra e estabelece um padrão de concentração de capital e de tecnificação do campo. A longo prazo a solução dos conflitos por terra ameniza a conflitualidade, o Estado exerce papel relevante na intervenção dos desencontros nas relações de poder.

A mediação de conflitos deve levar em conta os povos e comunidades, que devem ter seus direitos formalmente reconhecidos. A proteção as pessoas que sofrem violência, intimidação e ameaças deve ser assegurado. O combate a corrupção e ilegalidades dos órgãos oficiais relacionados a terra. As múltiplas formas de violência no campo devem ser investigadas, de modo que sejam julgados idealizadores e executores. 


\section{Referências bibliográficas}

AZAR, Zaira Sabry. GRANDES PROJETOS DE "DESENVOLVIMENTO": indicações sobre as relações de trabalho no campo no Maranhão. São Luís. Mimeografado, outubro de 2013. Anais do IV Jornada Internacional de Políticas Públicas. São Luís - Ma, 2009. Disponível em: <http://www.joinpp.ufma.br/jornadas/joinppIV/mesas/grandesprojetos-e assentamentos-rurais_ok.pdf>. Acesso em: 19 de maio de 2016.

BOBBIO, Noberto. Poder. In: BOBBIO, Noberto; MATTEUCCI, Nicola e PASQUINO, Gianfranco. Dicionário de Política. Brasília: Editora Universidade de Brasília, 1 ed., 1998. P. 933- 942.

CARNEIRO, Marcelo Sampaio. Terra, trabalho e poder: conflitos e lutas sociais no Maranhão contemporâneo. São Paulo: Annablume, 2013.

COMISSÃO PASTORAL DA TERRA (CPT). Conflitos no Campo Brasil. Goiânia: CPT Nacional, 2001-2015.

FERNANDES, Bernardo Mançano. Questão Agrária: Conflitualidade e Desenvolvimento Territorial. In BUAINAI, Antonio M. (Ed). Luta pela terra, reforma agrária e gestão de conflitos no Brasil. Campinas: Editora da Unicamp, 2005

FOUCAULT, Michel. História da Sexualidade 1. A vontade de Saber. 13a ed. Trad. Albuquerque, M. T. da C. e Albuquerque, J.A.G. Rio de Janeiro: Graal, 1999.

FOUCAULT, Michel. Microfísica do Poder. Tradução de Roberto Machado. organização, introdução e revisão técnica de Roberto Machado. 21. Ed. Rio de Janeiro: Graal, 2005.

INSTITUTO BRASILEIRO DE GEOGRAFIA E ESTATÍSTICA (IBGE). Censo 2010. Disponível em: <http://www.ibge.gov.br>. Acesso em: 27 de maio de 2015.

MORIM, Júlia. Quilombolas de Alcântara/MA. Pesquisa Escolar Online, Fundação Joaquim Nabuco, Recife. Disponível em: <http://basilio.fundaj.gov.br/pesquisaescolar>. Acesso em: 24 de maio de 2016. 2014.

PASQUINO, Gianfranco. Conflito. In: BOBBIO, Noberto; MATTEUCCI, Nicola e PASQUINO, Gianfranco. Dicionário de Política. Brasília: Editora Universidade de Brasília, 1 ed., 1998. P.225 - 229.

STEDILE, João Pedro. Questão Agrária. In: CALDART, R. S.; PEREIRA, I. B.; ALENTEJANO, P.; FRIGOTTO, G. (Org.). Dicionário da Educação do Campo. 1. ed. Rio de Janeiro, São Paulo: Escola Politécnica de Saúde Joaquim Venâncio, Expressão Popular, 2012. P. 641- 646. 